\title{
EXPERIMENTAL VERIFICATION OF INTEGRITY OF LOW-PRESSURE INJECTION PILES STRUCTURE - PILE INTERNAL CAPACITY
}

\author{
HENRYK PACHLA
}

ul. Lecha 16, 30-565 Kraków, Poland

\begin{abstract}
The idea of strengthening the foundation using injection piles lies in transferring loads from the foundation to the piles anchorage in existing structure and formed in the soil. Such a system has to be able to transfer loads from the foundation to the pile and from the pile onto the soil. Pile structure often reinforced with steel element has to also be able to transfer such a loading. According to the rules of continuum mechanics, the bearing capacity of such a system and a deformation of its individual elements can be determined by way of an analysis of the contact problem of three interfaces. Each of these surfaces is determined by different couples of materials. Those surfaces create: pile-foundation anchorage, bonding between reinforcement and material from which the pile is formed and pilesoil interface. What is essential is that on the contact surfaces the deformation of materials which adhere to each other can vary and depends on the mechanical properties and geometry of these surfaces. Engineering practice and experimental research point out that the failure in such structures occurs at interfaces. The paper is concentrating on presenting the experiments on interaction between cement grout and various types of steel reinforcement. The tests were conducted on the special low pressure injection piles widely used to strengthen foundations of already existing structures of historical buildings due to the technology of formation and injection pressure.
\end{abstract}

Key words: contact surface, foundation design, low-pressure injection piles, pile internal capacity

\section{INTRODUCTION}

Simple, reliable and secure drilling technologies along with beneficial economic conditions of their execution have boosted a rapid development of piles applications and implementation of indirect foundations in the process of foundation design.

The possibility of static transfer of loads from the existing foundations onto the pile supporting structure and the soil as well as the small weight of this structure create significantly safer and more favourable technical conditions for strengthening the already existing foundations than using traditional methods.

The pile installation in the existing foundation and soil creates a new foundation structure which forms a foundation-pile-soil system. This system has to be able to transfer loads from the foundation to the pile, inside the pile between its elements and from the pile onto the soil. From the point of view of continuum mechanics, the bearing capacity of such a system and deformation of its individual elements can be determined in analysis of the contact problem of three contact surfaces. Each of these interfaces is determined by different couples of materials. The couple that makes up the pile anchorage is the material from which the foundation is built (structure of rock and grout, brick and grout, concrete or reinforced concrete) and cement grout.

The pile structure is created by a couple of cement grout and steel reinforcement element. The pile-soil interface is made up of cement grout and soil. It is essential that on the contact surfaces the deformation of materials adhering to each other can vary (the conditions of inseparability are not fulfilled) and depends on the mechanical properties and geometry of these surfaces.

Additional conditions, suggested in [1], should be fulfilled for the foundation-pile-soil system to make the transfer of loading from the foundation to soil possible. The results of experiments carried out on the foundation-pile contact surface are also presented.

The tests on piles, particularly those of small diameters, presented in the literature, concentrate on their behaviour in soil. Since the strength and stiffness of the pile materials are significantly higher than the strength and stiffness of the soil, the analysis of pile structure seems to be secondary. Furthermore, cement grout is not widely used as a construction material in reinforced and composite structures. Therefore, in the literature there are no tests on the bonding between cement grout and reinforcement. There are few papers can be quoted although they do not deal strictly with 
piles but cement injected connections [2]. Such connections are also used in the process of wind power plants installation [3], [4].

The main goal of the present paper is to discuss the results of experiments performed by the author in order to examine the interaction between grout and different types of steel reinforcement of the pile (internal pile bond).

\section{PILE STRUCTURE - PILE INTERNAL BOND}

The pile formed in soil is subjected to the balanced system of forces that transfer loads from the foundation to the soil, such as friction forces acting on the pile shaft and normal forces acting on the pile base (Fig. 1). Therefore, the internal structure of a lowpressure injection pile has to be able to transfer these loads. While the strength characteristics of steel and cement grout are much better than those of the soil, the capacity of the cement grout-steel element bond on the interface surface strongly depends on the properties of this interface including its geometry and may be significantly lower. During uncovering of the foundation for research purposes, piles formed in the past can be discovered. In the case of piles reinforced with a perforated steel tube, the tube cover is often delaminated and damaged (Fig. 2). Since the forces acting on soil are to a large extent transferred through the skin friction on the pile shaft, so the failure of the interface induces the pile failure.

A significant and observed in engineering practice cause of the destruction of a pile structure is the loss of bond between the reinforcement and surrounding cement grout which builds the pile shaft. Due to the destruction of the internal structure the pile loses the ability to transfer loads to the soil, which determines the decrease in the internal pile capacity (loss of bond between cement grout and reinforcement). It is assumed that the pile internal capacity is determined by the maximum force at the steel-cement grout bond. Therefore, the process of bond destruction on the cement grout-reinforcement interface is determined by the value of shearing stress on the interface. The rate of this process is the propagation of defects on this surface and, in consequence, mutual slip of the bonded materials regardless of the boundary loading conditions on the pile periphery. In order to extort shearing stresses on the interface the experiments were conducted in static boundary conditions as shown in Fig. 3a, b.

In order to verify the usefulness of various steel elements used as cement grout reinforcement in lowpressure injection piles a series of experiments was performed to examine the bonding on typical reinforcement elements with cement grout. 258 specimens in total were examined in 8 series corresponding to various reinforcement elements and different loading schemes. Reinforcement elements used in engineering practice as anchors or sheet piling were also tested in a pull out test. The number of repetitions in each series was selected so as to meet the requirements of small statistical sample and to enable the statistical analysis of results. Each specimen was tested under continuously increasing axial loading applied directly to the reinforcement element by a YH-1000/50 actuator. The force was blocked by base plates of $20 \mathrm{~mm}$ thickness, close fitting to the bearing area covering the

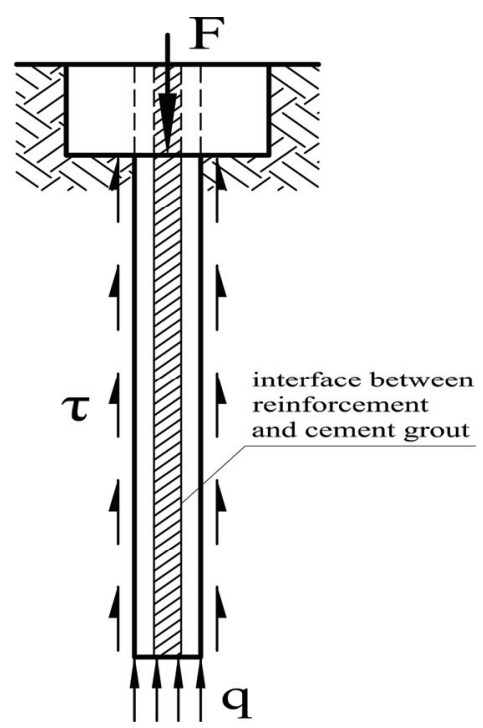

Fig. 1. A pile in soil under load
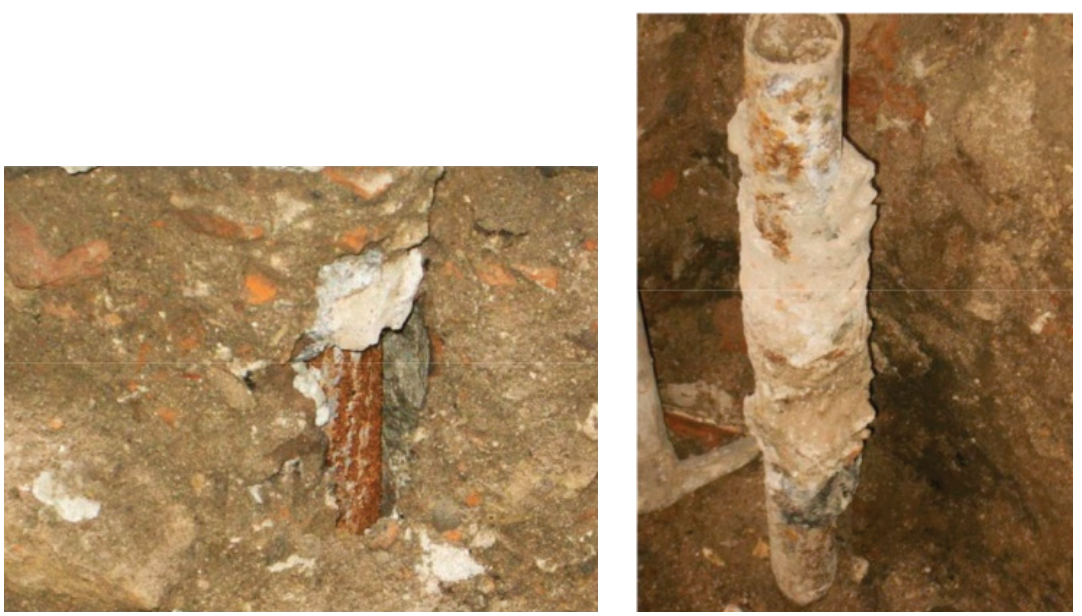

Fig. 2. Dug-up piles reinforced with steel tubes 


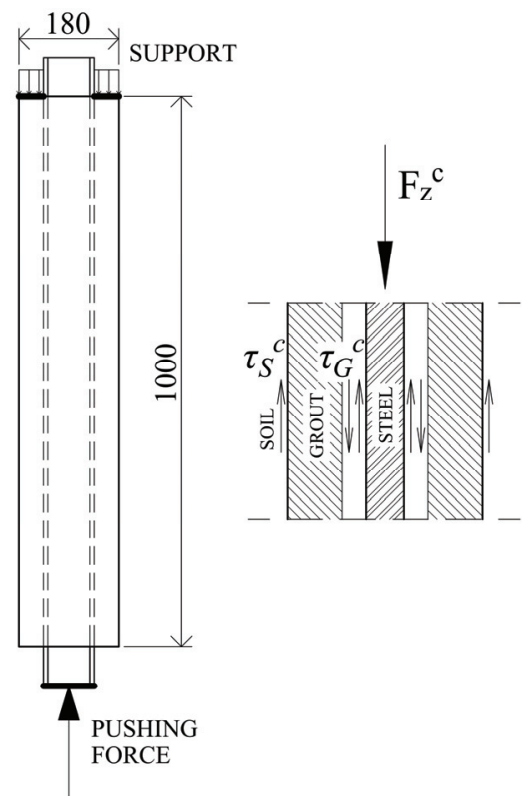

Fig. 3a. Push-in test

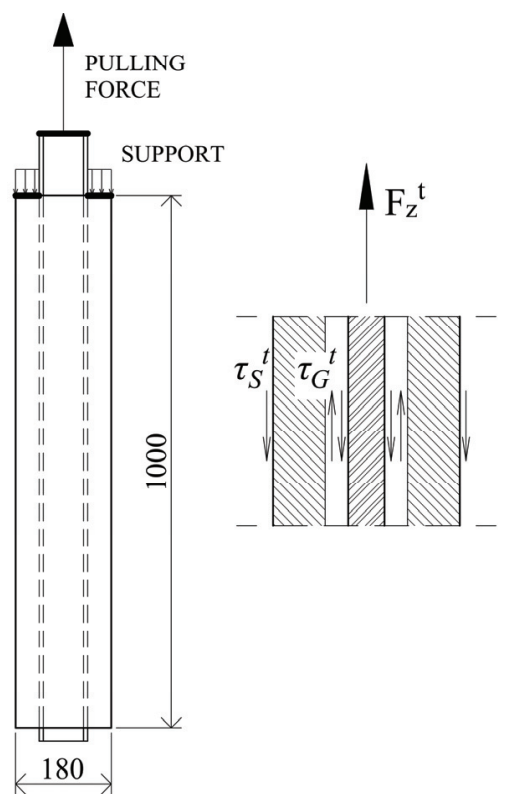

Fig. 3b. Pull-out test reinforcement. The displacement of reinforcement and pile periphery were measured constantly by WA $10 \mathrm{~mm}$ and $50 \mathrm{~mm}$ Hottinger Baldwin Messtechnik $\mathrm{GmbH}$ induction sensors. The force was measured using a C6A/2MN Baldwin Messtechnik GmbH sensor. All the values measured were registered constantly with force increment.

The specimens for all the tests were made from cement grout with the same water-cement ratio of 0.5 . The cement was obtained from the same factory. Each test was preceded by 28-day maturing of the pile element being tested. In all the tests the length of specimen was $100 \mathrm{~cm}$ to minimize the influence of disturbance induced by shearing stress acting in the area of application the load (resistance) which equalize the applied forces.

\section{PERFORATED STEEL TUBE AS A PILE REINFORCEMENT}

The first experiments were conducted on specimens reinforced with a perforated steel tube. The loading scheme was shown in Fig. 3a. In engineering practice a steel tube of $76.1 \mathrm{~mm}$ in diameter is the most common reinforcement for a small dimension injection pile. To check the influence of pipe stiffness on the bonding capacity (internal capacity) the specimens were prepared using pipes with walls 3.2 and $6.3 \mathrm{~mm}$ thick. The influence of thickness of the cement grout cover was also checked by preparing the specimens with a constant exterior thickness of cover (cylindrical samples) and on samples with various thickness of cover (specimens of square cross-section). The tests were performed on cylindrical samples with $180 \mathrm{~mm}$ diameter and square specimens of side length of $120 \mathrm{~mm}$ and $150 \mathrm{~mm}$. The maximum thickness of cement grout cover for the square samples of side length of $120 \mathrm{~mm}$ is similar to the cover thickness of cylindrical specimens. In the square specimens of side length of $150 \mathrm{~mm}$ the averaged cover thickness on the entire circumference corresponds to the cover thickness in the cylindrical samples. The experiment was performed on 30 square specimens of side length of $120 \mathrm{~mm}$ reinforced with a steel tube of wall thickness of $3.2 \mathrm{~mm}$, 30 square specimens of side length of $150 \mathrm{~mm}$ reinforced with a steel tube of wall thickness of $3.2 \mathrm{~mm}$ and 25 cylindrical specimens of $180 \mathrm{~mm}$ in diameter reinforced with a steel pipe of wall thickness of $3.2 \mathrm{~mm}$ and 25 cylindrical specimens reinforced with a steel pipe of wall thickness of $6.3 \mathrm{~mm}$.

For each series of experiments the probability of distribution of force in the interface between reinforcement and cement grout $\left(\tau_{z}^{c \max }\right)$ at failure is presented in Fig. 4. The normal distribution was adopted as a basis of analysis. In each case the average values $\left(R_{A V}\right)$, standard deviation $(\sigma)$ and guaranteed value $\left(R_{G}(5 \%)\right)$ were determined. It was assumed that the probability of occurrence of the averaged stress on the interface at failure, lower than the guaranteed one is not higher than $5 \%$.

The results of experiments indicate a significant influence of the outer cement grout cover thickness 


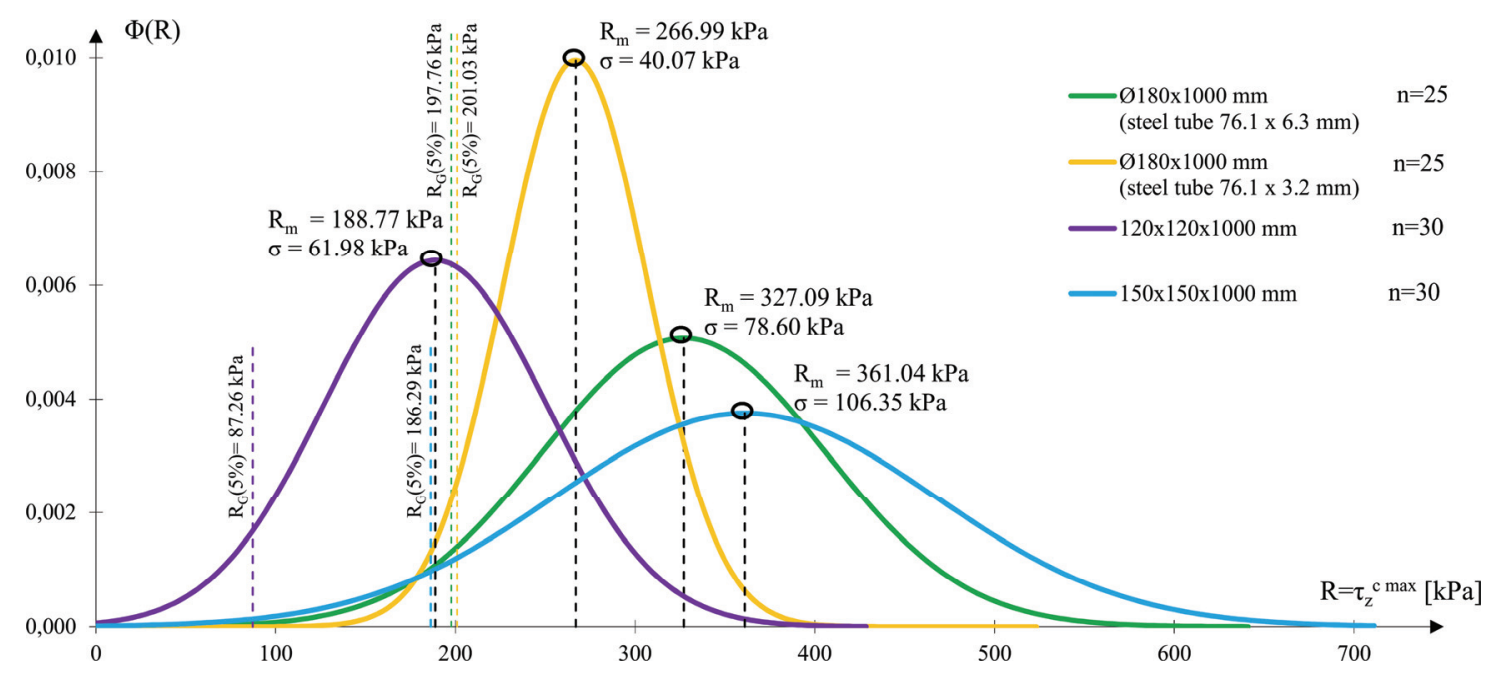

Fig. 4. Normal distributions of the strength of reinforcement - cement grout bond cylindrical and cuboidal specimens ( $n$ - number of tested samples)

(reinforcement cement cover) on the average bond strength between the steel pipe and cement grout - the thicker the cover the higher the average strength of the connection. It is prominent that the strength depends on the cover thickness over the entire contact surface. In the samples of square cross-section of side length of $150 \mathrm{~mm}$ the cover thickness varied from $36.95 \mathrm{~mm}$ to $68.02 \mathrm{~mm}$. Its average value of $52.48 \mathrm{~mm}$ was approximately equal to the constant cover thickness in the cylindrical samples $180 \mathrm{~mm}$ in diameter, i.e., $51.95 \mathrm{~mm}$. Nevertheless, the average bond strength was significantly higher in the samples with locally thicker cover (square cross-section) while in samples where the cover reached this thickness only locally (square cross section samples of side length of $120 \mathrm{~mm}$ ) the average bond strength was much lower.

The results presented above indicate that local thickening of reinforcement cover, which increases the distance between the reinforcement and the pile side surface, is beneficial for the entire steel-cement grout-interface.

The average thickness of the cover is crucial for the guaranteed bond strength level of 5\%, significant in the design process. For cylindrical specimens $180 \mathrm{~mm}$ in diameter and cuboidal specimens of $150 \times 150 \mathrm{~mm}$ cross section, which have similar average thickness of the cover, the values of guaranteed bond strength varied insignificantly.

The analysis of the results of experiments conducted on specimens reinforced with perforated steel tubes of the wall thickness of $3.2 \mathrm{~mm}$ and $6.3 \mathrm{~mm}$ indicated similar relationships to the above-described. For the tube almost twice thicker the average value of shear stress at failure was about only $20 \%$ higher. The values guaranteed at $5 \%$ were similar and the differ- ence between them was $1.6 \%$. Thus, the increment of the strength of the steel reinforcement element was less important.

The similar values of guaranteed strength were obtained for both different thicknesses of the steel pipes and similar average thickness of steel element cover. Much lower values of average and guaranteed bond strength were obtained for a smaller average thickness of the cover in the cuboidal samples of $120 \times 120 \mathrm{~mm}$ cross section. It can be stated that for a fixed steel reinforcement element the thickness of the outside cover of reinforcement has a crucial influence on the bond strength of the steel-cement grout interface.

\section{PILES REINFORCED WITH STEEL SECTIONS AND SAS SYSTEM REBARS}

To check the effect of geometry of the interface between reinforcement and cement grout the tests were carried out on cylindrical elements of $180 \mathrm{~mm}$ in diameter and $1 \mathrm{~m}$ in length reinforced with I-beam 100 and SAS system rebars of $35 \mathrm{~mm}$ in diameter (Fig. 5a-c). The force was applied to the specimens as shown in diagrams in Fig. 3: pressing the reinforcement into the specimen (Fig. 3a) and pulling it out of the specimen (Fig. 3b). An additional loading scheme (Fig. 3b) was added to the experiment because this type of reinforcement is employed in bent piles and anchors pulled out from soil. As before, each test was performed after 28 -day maturing process. The number 


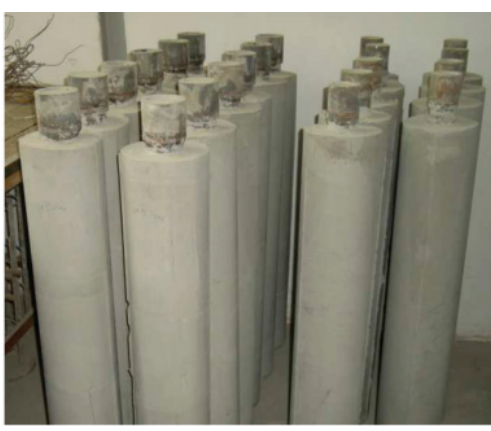

Fig. 5a. Pile specimens with steel tube reinforcement

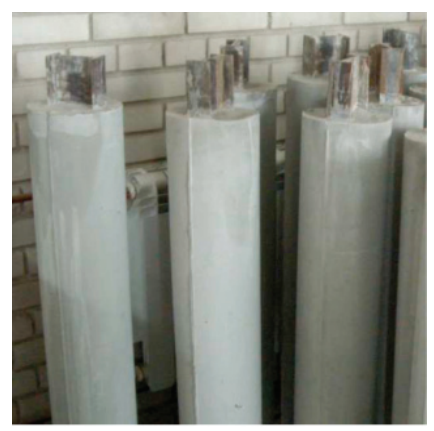

Fig. 5b. Pile specimens with $\mathrm{I} 100$ reinforcement

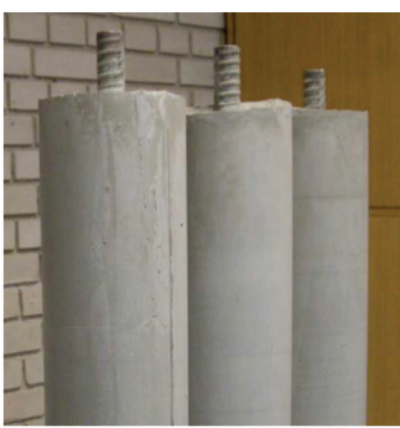

Fig. 5c. Pile specimens with SAS system rebars

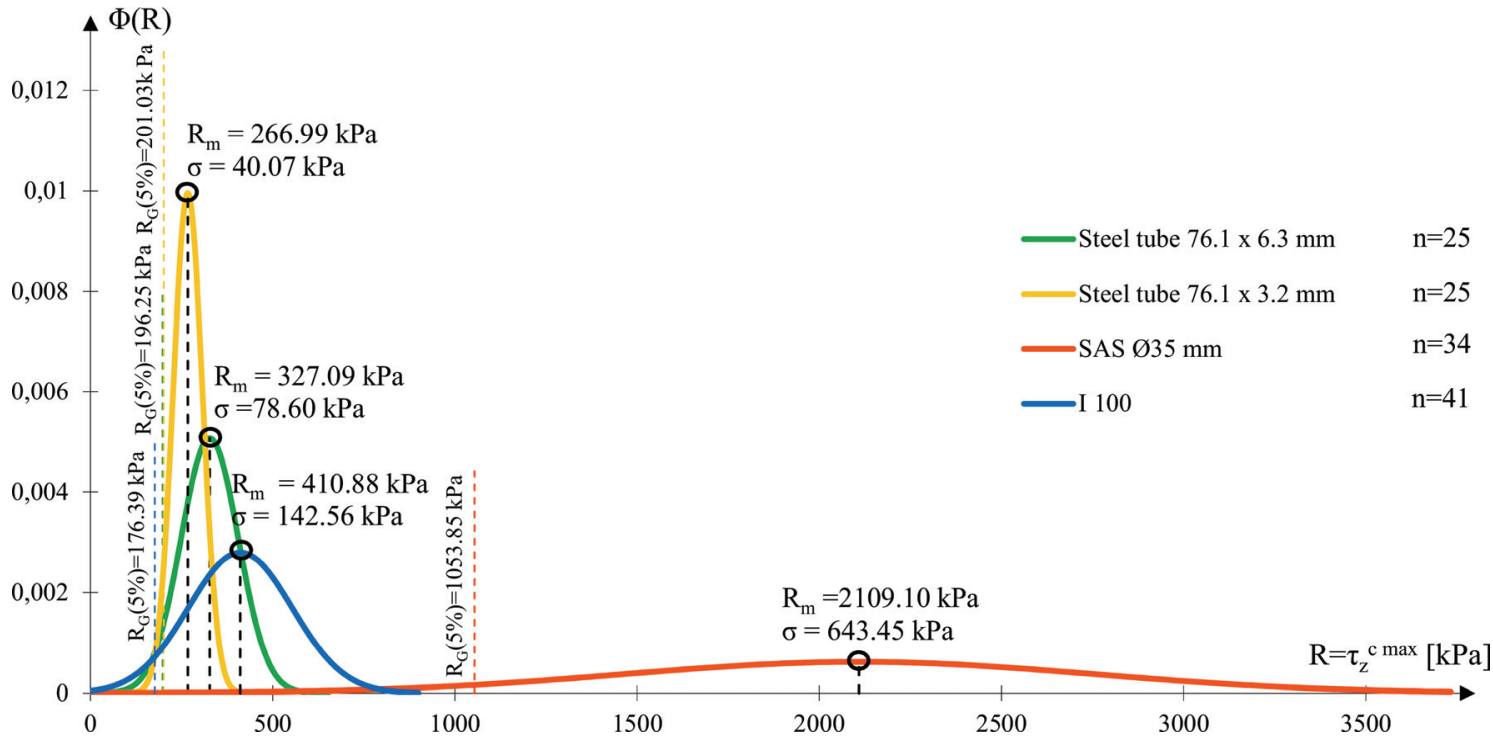

Fig. 6. Comparison of normal distributions for specimens examined according to the diagram presented in Fig. 3a (push-in test) ( $n$-number of tested samples)

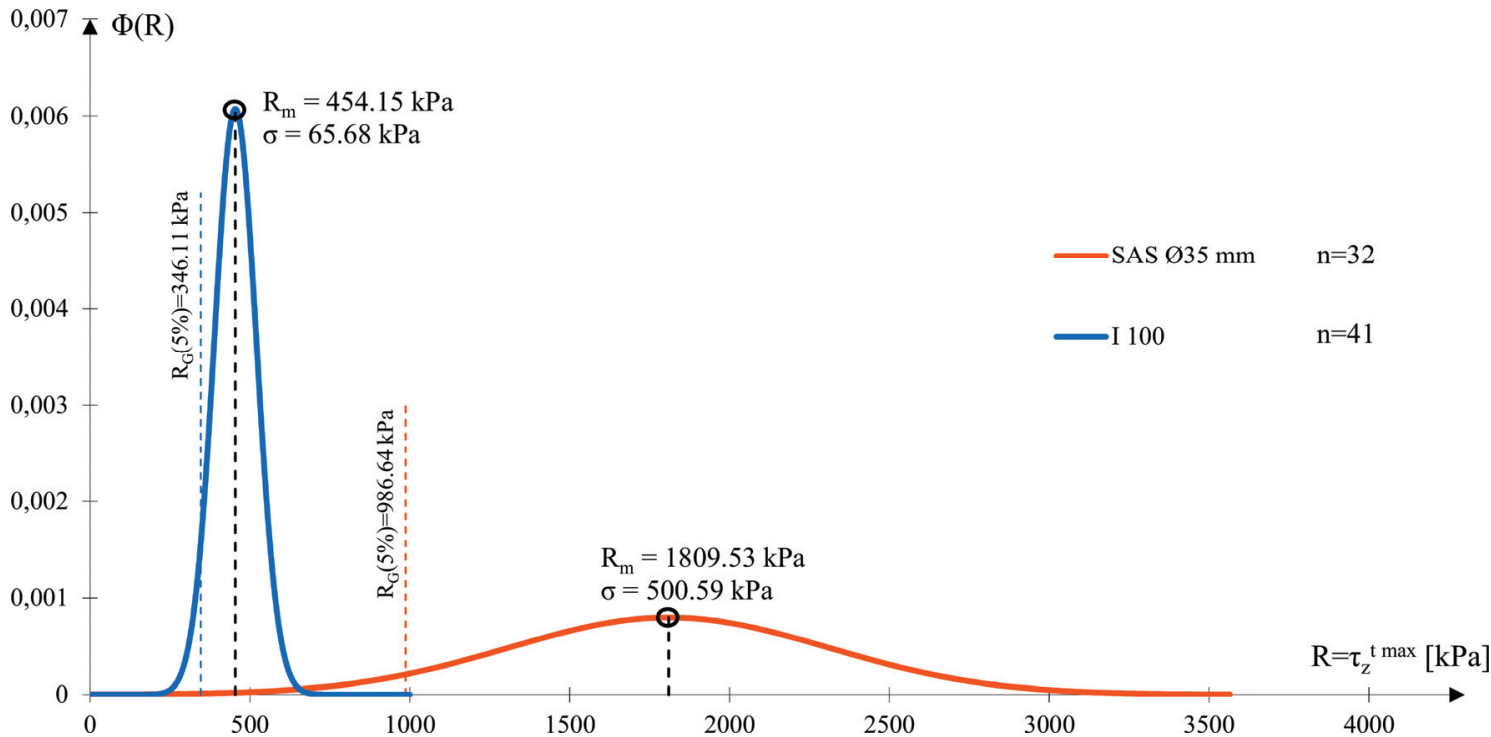

Fig. 7. Comparison of normal distribution for specimens examined according to the diagram presented in Fig. 3b (pull-out test) ( $n$ - number of tested samples) 
of samples in each set of tests was 41 in both push-in test (Fig. 3a) and pull-out test (Fig. 3b) of specimens reinforced with steel sections. 82 specimens in total were examined. In the case of SAS system rebars 34 specimens were used in push-in test and 32 specimens in pull-out test.

In Figures 6 and 7 probability distribution of shear stress at failure at the steel element-cement grout bond, averaged on the interface is shown. For comparison the following distribution characteristics were included: mean values, standard deviation and value guaranteed at $5 \%$.

For different steel reinforcement elements the highest mean values of bond strength were obtained for SAS rebars. These results were obtained in both push-in and pull-out tests, with the average value of strength obtained in push-in higher than that in pullout tests. Similar results were obtained for the guaranteed value, however, the difference between the push-in and pull-out values was much smaller. The reason was the increase of the standard deviation along with the increase of the average value. For the 100 I-beam reinforced samples the mean values were much lower than for SAS rebars (up to 4-5 times lower) but higher than in the case of reinforcement made of perforated steel tubes. The significant difference between steel bars reinforcement and steel elements of smooth surface is accounted for by much higher adhesion due to the ribs on bars' surface. It should be pointed out that in the case of I-beam reinforcement the average value and the value guaranteed at $5 \%$ value of the bond strength in push-in tests were lower than in pull-out tests, i.e., the opposite than for ribbed SAS rebars.

The significant difference in the probability density function in Figs. 6 and 7, i.e., susbtantial curve flattening for SAS system rebars relative of I-100 could raise doubts. The destruction forces recorded during the experiments determined the probability density function parameters which did not differ from each other significantly. For SAS system rebars in push-in test these parameters were: the mean value $231.91 \mathrm{kN}$, standard deviation $70,75 \mathrm{kN}$. In pull-out test the mean value was 198.97 , standard deviation $55.04 \mathrm{kN}$. For I-100 the probability density function parameters were: in push-in test - the mean value $152.03 \mathrm{kN}$, standard deviation $52.75 \mathrm{kN}$; in pull-out test - the mean value $168.03 \mathrm{kN}$, standard deviation $24,30 \mathrm{kN}$. Higher breaking loads for SAS system rebars than for I-beams referred to the SAS system rebars interface several times smaller than for that of I-beams, caused a significant difference in the corresponding values of the mean shear stress (breaking loads referred to the area of bond interface). The standard deviation as a probability density function parameter is square denominator in the exponential function and multiplier denominator in this function. Only for strictly analytical reasons the deviation determines the significant flattening of the probability distribution function for SAS system rebars relative of the same curve for I-beams.

The above-presented results of tests on different pile reinforcement steel elements indicate that apart from cement grout cover thickness the properties of the interface between steel and cement grout crucially affect the bond strength (pile internal bearing capacity). Both the area of this interface and its geometry are significant.

The various values of the internal capacity are observed at different loading scheme so the manner of load application is also important.

\section{INTERNAL CAPACITY RELATED TO EXTERNAL CAPACITY}

In order to make full use of soil strength properties the external capacity should be reached sooner than the internal capacity.

Low pressure injection piles are formed by drilling a borehole, bringing the excavated material to the surface, and making a low pressure injection into the borehole "from below" by the injection tube. After drilling the borehole and before its injection with cement grout the boundary conditions on the borehole surface constrain a zero state of normal stress. If the saturated soil medium, the hydrostatic pressure and additional ground loading are disregarded in the considerations, the pile is formed in a stable soil medium and there is no earth pressure.

Low pressure injection piles have a small cross section area, in which the pile periphery area is predominant and the pile base area is relatively small. The pile base contributes very little to the transfer of forces acting on the pile. For comparative purposes also stresses normal to pile cross-section area were disregarded.

Analysing the conditions of forces equilibrium acting on the pile shaft (interface between cement grout and soil) and on the interface between cement grout and reinforcement (Fig. 3), the stresses which correspond to the state of equilibrium on both contact surfaces can be determined. Consequently, the condition of work admissibility for the pile structure (cement grout-reinforcement bond) is the same value of 
the soil resistance and the bond guaranteed strength referred to the shaft surface. Figures 8 and 9 present comparison of the guaranteed bond strength calculated as a force destroying the pile structure bonds and referred to the pile side surface for the obtained test results (a colourful dotted lines) and the soil ultimate passive pressure for cohesive and non-cohesive soils (continuous line) for the tests results. The values of the soil ultimate passive pressure were adopted according to the Polish standard [9]. For soil parameters the partial material factor 1.1 was adopted. The areas below the dotted lines denote the ranges in which the loss of bond between cement grout and reinforcement (internal bearing capacity) determines pile bearing capacity.

The idea of strengthening the foundation using injection piles lies in transferring loads from the foundation to firmer layers located deeper. It can be con- cluded from the graphs presented in Figs. 8 and 9 that the internal pile capacity can be crucial for the capacity of piles located in firmer soils. For the piles $120 \mathrm{~mm}$ in diameter reinforced with a perforated steel tube extensively used in the past, the bond strength and internal capacity are so low that contribution of mechanical properties of soil in foundation strengthening could not be used. When the pile diameter is increased to $180 \mathrm{~mm}$, the internal capacity still remains crucial in a significant range of soils.

The results of the push-in tests conducted on the piles specimens with I-beam reinforcement indicated much better parameters of the interface and internal capacity higher than in the case of perforated steel pipes. However, still in the firmest soils the internal capacity was reached sooner than the external. Over the entire range of soils while the I-beam is pulled out from the pile according to the scheme presented

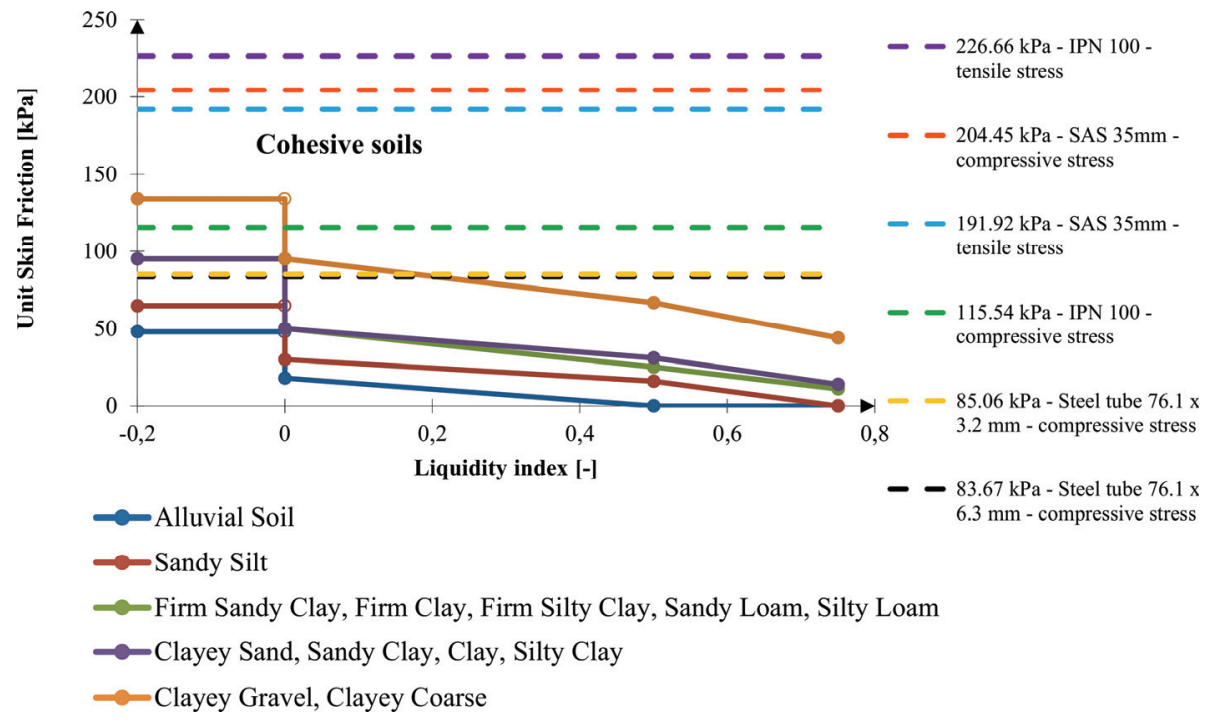

Fig. 8. Comparison of bond guaranteed strength and soil ultimate lateral pressure against pile shaft for cohesive soils

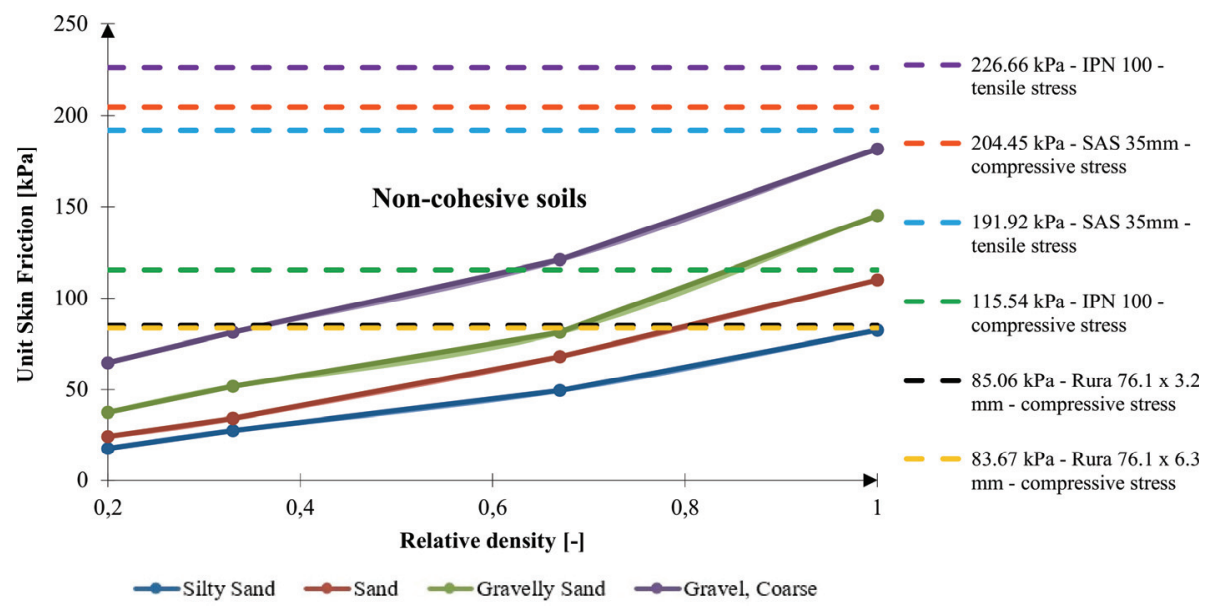

Fig. 9. Comparison of bond guaranteed strength and soil ultimate lateral pressure against pile shaft for non-cohesive soils 
in Fig. 3b for the whole soils range the soil skin friction (external capacity) decides of the pile capacity. In this case the internal pile capacity was sufficient (Figs. 8, 9).

The internal capacity of the piles reinforced with SAS ribbed rebars was also sufficient in both push-in and pull-out over the entire range of cohesive and non-cohesive soils.

The criterion of admissibility for pile reinforcement elements presented above is given for reference only and its aim is to point out that the internal pile capacity in many cases can be crucial in their design. This is because the adopted values of passive pressure used in the Polish Standard [9] give a considerably underestimated value of the external capacity for lowpressure injection piles compared to the values obtained from the experiments. They are also significantly lower than those proposed in the European standard [10]. They also differ from the capacities calculated from the formulas proposed by other authors [5]-[8]. Therefore, in engineering practice the influence of internal capacity can have much more significant effect on the correct design of low-pressure injection piles.

\section{SLIP ON CEMENT GROUT-REINFORCEMENT INTERFACE}

Figure 10 illustrates the displacements of a SAS steel bar relative to cement grout cover (slip on the interface) in pull-out tests (results for different samples are marked with colours).

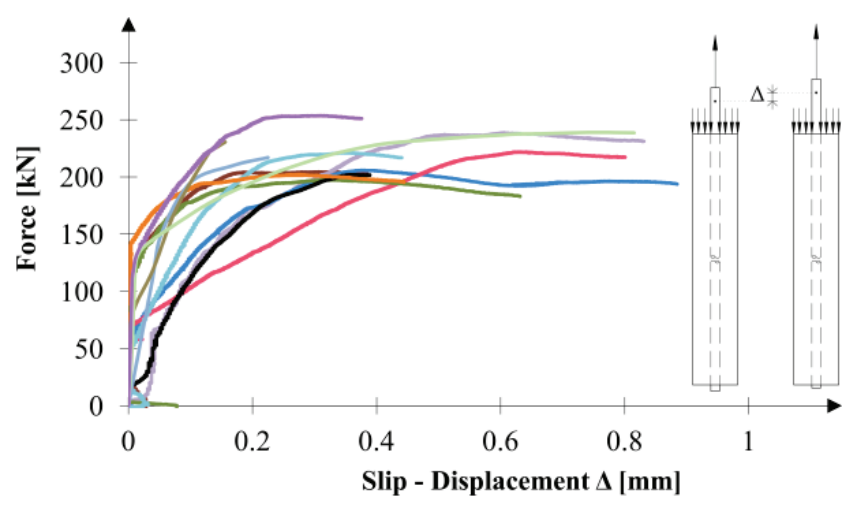

Fig. 10. Force versus displacements of SAS steel ribbed bar relative to cement grout cover

In the first stage the load increment was followed by a relatively small increment of slip displacement. Only when the load reached values greater than $0.7-0.8$ of failure load a rapid slip increment occurred and led to the loss of bond between the two materials and then destruction of the specimen. The slip process was different for a plain steel element. Figures 11 and 12 illustrate slip displacements between I-beam and cement grout in both push-in and pull-out tests after the schemes shown in Figs. 3a and 3b (results for samples selected for presentation are marked with colours). What is important is that considerably high values of slip displacements were recorded from the very beginning of the experiment in both cases of the loading scheme. In push-in the limit slip displacements reached the values from 0.5 to $2 \mathrm{~mm}$.

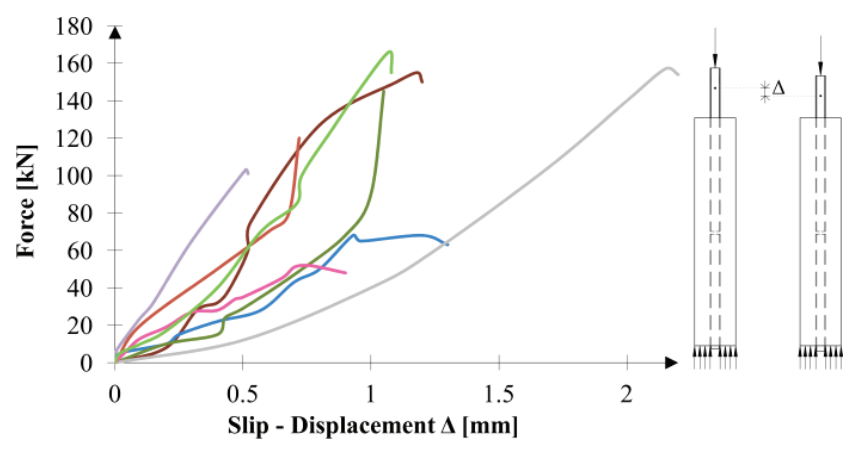

Fig. 11. Force versus slip in push-in test (I100)

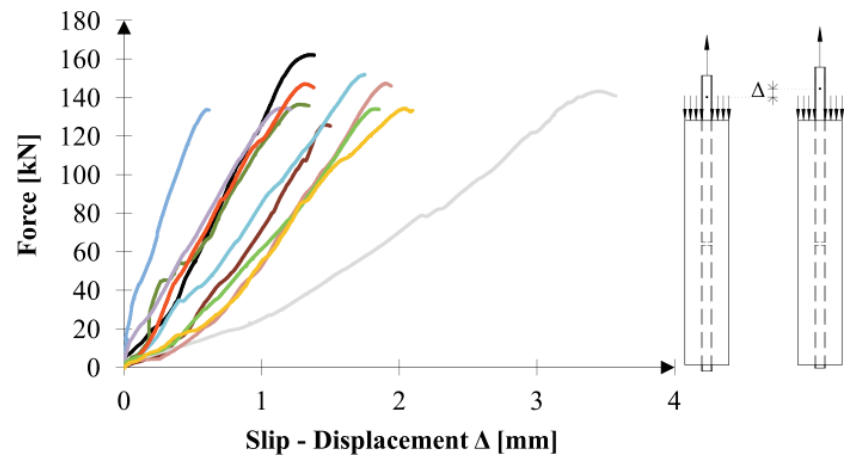

Fig. 12. Force versus slip in pull-out test (I100)

When the steel element was pulled out from the pile this displacement was significantly greater - the values ranged from 0.5 to $4 \mathrm{~mm}$. When the steel section was pushed into the pile the skin friction was greater than in the pull-out test due to different signs of transversal strains in the steel element.

\section{FINAL REMARKS}

In the design of injection piles reinforced with various types of steel elements particular attention should be paid to the bonding efficiency between cement grout and steel. The theory of composite structures includes a number of conditions which may not 
be fulfilled for a pile as a structural element. The loss of bond is followed by the destruction of steel element cover formed from cement grout which makes the pile shaft. The consequence of shaft destruction is the loss of pile bearing capacity.

The design of steel-cement grout bond cannot be based on extensive experimental background of steelconcrete composite structures. The bond parameters adopted for composite structures are not valid for cement grout. The design ultimate shear strength on the steel-concrete interface [11] of $0.3 \mathrm{MPa}$ for concreted steel sections, below which a coupler (connector) is not required, could serve as an example. When the steel section is covered with cement grout the loss of bond occurs at much lower values. In the tests results for steel sections and steel pipes analysed in the paper this value was recorded at the level as low as $0.2 \mathrm{MPa}$.

The tests presented in the paper confirm a limited field of applicability of both steel pipes and steel sections as pile reinforcement not only in pushing such a composite element into the soil (the pile) but also in pulling it out from the soil (soil anchor). In consequence, the limited field of applicability is extended also to bent pile elements including commonly used retaining walls reinforced with steel sections. Therefore, the application of composite elements for constructing piles or anchors as well as retaining walls should be verified experimentally. It seems necessary to conduct a series of experiments that would result in determination of the mechanical parameters for both the bond and cement grout tested itself as a structural element.

The slip between the materials on the bond surface also requires further attention. The conducted experiments indicate that mutual displacements of the two bonded materials are initiated as soon as the application of axial load starts regardless of the force direction. Slippage increases with the load, which leads to the loss of bonding. The values of strains obtained from experiments point out the necessity of including them in a thorough analysis of the deformation of the foundation-pile-soil system.

\section{REFERENCES}

[1] PaChla H., Conditions of proper interaction of low-pressure injection piles (LIP) with structure and soil, carrying capacity of pile anchorage foundation, Studia Geotechnica et Mechanica, 2016, Vol. 38, No. 4, 33-49.

[2] Dowling P.J., Elnashai A.S., Carroll B.C., A New Pressurised Grouted Connection for Steel Tubulars, Journal of Constructional Steel Research, 1983, Vol. 3, No. 3.

[3] Tziavos N., Hemida H., Metje N., Baniotopoulos C., Grouted connections on offshore wind turbines: A review, Proceedings of the ICE - Engineering and Computational Mechanics, 2016.

[4] Dallyn P., El-Hamalawi A., Palmeri A., Wear in large diameter grouted connections for offshore wind energy converters, Proceedings of the 10th International Conference on Advances in Steel Concrete Composite and Hybrid Structures, Singapore: National University of Singapore, 2012, 8.

[5] Philipponnat G., Methode pratque de calcul d'un pieu isole a l'aide du penetrometer statique, Revue Francaise de Geotechnique, 1980, 10, 55-64.

[6] Bustamante M., Gianeselli L., Pile bearing capacity predictions by means of static penetrometer CPT, Proc., 2nd European Symp. On Penetration Testing, ESOPT-II, Amsterdam, The Netherlands, 1982, Vol. 2, 493-500.

[7] Gwizdala K., StęCZniewsKi M., DyKa I., Wykorzystanie sondowań statycznych do obliczania nośności i osiadań pali, Nowoczesne Budownictwo Inżynieryjne, 2009, 4(25).

[8] GwizdaŁa K., Fundamenty palowe, technologie i obliczenia, t. 1, Wydawnictwo Naukowe PWN, Warszawa 2010.

[9] PN-83/B-02482. Fundamenty budowlane. Nośność pali i fundamentów palowych.

[10] PN-EN 1997-1:2008, Eurocode 7 Geotechnical Design, PKN, Warsaw, Poland.

[11] PN-B-03300. Konstrukcje zespolone stalowo-betonowe. Obliczenia statyczne i projektowanie. Polski Komitet Normalizacyjny, August 2006. 